\title{
Reviews
}

The Person and the Challenges

Volume 11 (2021) Number 2, p. 287-290

DOI: http://dx.doi.org/10.15633/pch.4085

Paweł Mąkosa

ORCID: https://orcid.org/0000-0002-4664-7024

The John Paul II Catholic University of Lublin, Poland

\section{Presentation of a multi-author monograph entitled $A$ healthy and strong family as the foundation of socjety edited by Rev. Józef Stala, Krakow 2019, pp. 233, ISBN 978-83-7438-760-6}

The family is a natural and irreplaceable environment for human development, not only in the biological, but also in psychological, social or religious spheres. Thus, one should be satisfied with this multi-author monograph entitled $A$ healthy and strong family as the foundation of society, which is another publication in the series Family Studies published by the Scientific Publishing House of the Pontifical University of John Paul II in Kracow and edited by wellknown and respected specialists - Elżbieta Osewska and Rev. Józef Stala. This monograph demonstrates the mutual interaction of family, society, State and the Church. Attention has been drawn to the fact that the family builds human communities and they, in turn, should support the family. This monograph consists of an introduction and three following parts: The situation of the modern family: opportunities and threats; Holistic marriage and family support; Upbringing in a family and in cooperation with a family.

The first part of the monograph consists of six chapters devoted to an understanding of the situation in which modern families function. Ilona Bartocha-Galik 
analyses the changes regarding the family from a sociological perspective and in this context indicates an increase in the number of divorces and alternative forms of married and family life. As the subject of her study, Urszula Miernik has chosen the motherhood of teenage girls in the context of family policy. The author rightly notes that state care is essentially limited to legal regulations, whereas there is the need for a comprehensive understanding of the situation of minor mothers and for specialist counselling. Another author, Krystyna Jankowska, attempts to explore the mutual determinants of suicide among children and young people and the situation in their family. She also postulates action to be taken in order to acquire knowledge regarding this problem, but also to strengthen family ties and to build a proper hierarchy of values. Szymon Peterman has prepared an article entitled Anti-social behaviour of children and young people from families affected by domestic violence, in which he indicates numerous causes of anti-social behaviour of children and presents suggestions for overcoming them. It is worth paying special attention to the article of Rev. Andrzej Zwoliński under the meaningful title Children 'to order', in which he analyses artificial insemination and genetic engineering used to create the desired human genome. He presents a thorough and in-depth analysis of this issue, referring to the latest scientific achievements. He presents the Catholic stance, but also discusses natural law on the main issues. Undoubtedly, this article is a clear impulse to reflect upon issues related to the dignity of children and their rights. Magdalena Syga, who has devoted her research to personality and axiological predictors of adaptation to the life situation of emigrants and their families, is the author of the last article in the first part of the monograph. The author first characterises the phenomenon of migration and the adaptation process, then goes on to examine the role of personality in this process and the relationship between life values and adaptive behaviours. In subsequent research stages, on the example of Polish emigrants in the Netherlands, she determines the relationship between personality, hierarchy of values, having a family and adaptation to life in exile.

The second part of the multi-author monograph under review consists of five articles. Aneta Paneth has prepared a study entitled Strengthening marriage and family ties based on the activities of the foundation called Family in the service of humans in Rychwałd, in which she studies various forms of activity of this foundation, emphasising not only therapeutic but also preventive measures. In turn, Monika Urbańska analyses mediation in family matters, understood as out-of-court dispute resolution. The author examines the essence 
of mediation in family matters as well as the person of a mediator and the principles of mediation. Krystian Wojaczek is the author of another article entitled Prevention of a marriage crisis as a way to a healthy society, in which he clarifies the meaning of the term 'marriage prevention' and draws attention to the cooperation of the Church and the state in this matter. He boldly draws attention to the negligence and errors that, in his opinion, occurred on the side of the Church in Poland. It seems that the author is factually correct, although he rarely supports his theses with sources or studies. Another article in the second part of the monograph is a paper by Paweł Landwójtowicz entitled Work with relational trauma in couples therapy. The author emphasises the importance of becoming aware of the meaning of traumas experienced by people in relationships with individuals significant for them in the early stages of life, and then refers to the possibility of treating such traumas. In the next article entitled Foster parenting in the light of the principle of subsidiarity, Klaudia Słowik analyses issues related to raising children in foster families. The author provides statistics on the number and typology of foster families in Poland and focuses on the operationalisation of the subsidiarity principle, giving examples of its application in foster parenthood.

The last, third part of this study is entitled Education in the family and in cooperation with the family and consists of three chapters, the first of which, written by Rev. Jan Kochel, deals with the spiritual pedagogy of love and focuses on justifying the need for purity. The First Letter of St. Paul to the Corinthians constitutes the basis of the analysis. Aware of the adversities that the understanding of purity is experiencing today, the author points to a new understanding of upbringing to observe it. On the other hand, Elżbieta Osewska has chosen to analyse the issue of education strengthening the national identity of Poles implemented by Polish schools in Leuven, Belgium. The author studies the contribution of these schools to the education of young Polish immigrants, especially in relation to Polish culture and language. The last chapter of the monograph is entitled The role of the family in shaping patriotic attitudes. Rev. Władysław Majkowski, the author, points to the family as the basic environment for socialisation, including patriotic education. He states that patriotism is not only an emotional attitude to the value of one's own culture, but also the ability to sacrifice oneself for the homeland. He also warns against perversions such as cosmopolitanism, nationalism, and postmodernism.

A review of all 14 chapters of the monograph allows one to state that they have been devoted to important issues concerning broadly understood care for the 
family which is the environment of human birth, development and education. Undoubtedly, this book is a valuable contribution to the scientific reflection on the modern family and its problems. 